\title{
Initiative on engaging the under-graduate medical students in implementing the 5S-KAIZEN at Faculty of Medicine, Fayoum University
}

\author{
Naglaa A. El-Sherbiny • Eman H. Ibrahim` Asmaa Younis
}

Public Health Department, Faculty of Medicine, Fayoum University, Egypt.

*Corresponding author. E-mail: emanhanafy1946@gmail.com.

Accepted $24^{\text {th }}$ December, 2018.

\begin{abstract}
Integration of 5S-KAIZEN concepts into the medical curriculum of Public Health prepares the medical graduates with meaningful contributions to the mission of Continuous Quality Improvement (CQI). This paper aims to display the experience and impact of introducing the 5S-KAIZEN into the public health curriculum. A horizontal integration model was used in teaching the students the basic theoretical part of 5S-KAIZEN within a finite period of time followed by the practical application. The students achievements were evaluated with different methods included; written report, preparation of power-point presentation, a written exam, performance evaluation and MCQ. Students were able to evaluate the working environment; skilful in writing a report, clearly understood the required skills for a productive workplace. Findings suggest that 5S-KAIZEN is needed to be aligned as a requirement for graduation from all the postgraduate medical programs.
\end{abstract}

Keywords: 5S, continuous quality improvement, public health, medical students, curriculum, Fayoum University.

Abbreviations: PDCA: Plan, Do, Check and Act; ENT: Ear, Nose, and Throat; MCQs: Multiple choice questions; CQI: Continuous Quality Improvement; KAB: knowledge, Attitude and Behavior.

\section{INTRODUCTION}

5S-KAIZEN is a systematic method of organizing and standardizing the workplace for lean healthcare (Kanamori et al., 2015). As a result of the low-cost and limited use of technology, the $5 S$ methodology has been widely used in different areas of the world (Chitre, 2010; Mallick et al., 2013; Pentti, 2014; Purdy et al., 2013) to improve and integrate, the processes and services of health institutions (Shaman and Sanjiv, 2015). The KAIZEN is a problem-solving technique depends on quality cycle PDCA and practices for continuous improvement (Gapp et al., 2008).

The five words of $5 S$ were derived from equivalent Japanese words which also start with a letter "S". The first (S) in Japanese words is (Seiri) or Sorting all tools and materials in the work area and only keeping the items that are essential; the second (S) is (Seiton) in Japanese words or Setting the tools, equipment, and parts so that they encourage workflow; the third (S) of Japanese words is (Seiso) or Shinning to keep the workplace clean and neat. While the most important two Phases are Standardize (Seiketsu) and sustain (Shitsuke); this means that work practices operate consistently and in a standardized manner. The last $S$ is (Shitsuke); Sustaining through maintaining high standards by proper follow-up. $5 \mathrm{~S}$ has become $6 \mathrm{~S}$, as safety is considered to be the sixth element. $5 S$ has 
recently adopted by The Japan International Cooperation Agency (JICA) as a potential solution to improve the service quality of health-care service quality and has assisted several low- and middle-income countries (JICA, 2013).

Educational institutions for health professionals do not only train healthcare personnel to work in health facilities but also equip them with managerial skills, to be ready to work at different levels of the health system. Therefore, medical curricula are exposed to several changes and modifications in the content and associated methods of teaching and assessment to accommodate the transferability toward teaching students new competencies (Sanders and Welk, 2005). The Public Health curriculum prepares the medical graduates to learn by doing in order to be successful healthcare providers, develop new competencies helping for a better understanding of work (Huston, 2013).

The 5S-KAIZEN approach provides students with an opportunity to work collaboratively with other health professionals, be accountable to measure their performance and improve the quality of care, manage efficiently the available resources and target not only the healthcare providers' safety but also the patients (Graban, 2015; Donald and Jonathan, 2010).

The content of Public Health curriculum covers a variety of topics delivered over one academic year. The fourth-year medical program is covered by 4 subjects, Public health and community medicine, Forensic and toxicology, ENT and Ophthalmology. The students are divided into four groups. Each group must spend two months in each department getting theoretical sessions and practical activities in each curriculum. The beginning of the 5S-KAIZEN integration into the fourth-grade medical curriculum was started when a consensus has emerged that it's not enough for medical students to be taught the medical sciences, they also need to know how to create an effective, disciplined, productive working environment in the real world of hospitals.

The current initiative of integration the 5S-KAIZEN into the fourth-grade medical curriculum provided the students with both the educational aspects and implementation methods of $5 \mathrm{~S}$. The current Curriculum modification provides professional guidance to support the future graduates and make the 5S-KAIZEN part of their thinking and behavior and to get them more involved in the management process (Nimnath et al., 2007).

\section{Aim of work "Core of Matter"}

The originality and value of the paper is derived from the necessity to ease the future doctors into the process of quality improvement through practical understanding the intimate connection of 5S-KAIZEN and the process of quality improvement at both system and process level for achieving a higher productivity, safety in the workplace and better healthcare outcomes. To maintain this ethos, a combination of both structured teaching and active participation were introduced in teaching the 5SKAIZEN approach.

This initiative proposes a model emphasis on three key areas of engagement, consolidation, and implementation that would systematically allow for gradual transition of medical students from passive to active participation. Saeed and others urged that when students have developed an understanding of QI, they can then consolidate this in the later years of medical school before going out and participating in QI in a clinical context.

The core values of team building, decision making and leadership skills must be instilled in future doctors at medical school. As suggested by Sanders and Welk (2005), moving towards complex skills will be important to implement strategies of proximal development. The medical students need to understand the inter-relation of the five steps of 5S-KAIZEN to maintain a convenient, safe work environment, improve productivity, efficiency, solve most workplace-related problems, reduce time and waste and keep good staff communication.

\section{METHODOLOGY: THE PROCESS OF INTEGRATION}

The six stages approach used by Kern et al. (1998) was followed in designing the 5S-KAIZEN course. The first stage was the problem identification as medical education focuses on clinical examination without paying attention to teaching students how to manage the workplace, the second Stage focused on doing professional and market's needs assessment, the third Stage was setting the goals and objectives of the course, the fourth stage was formulating the educational strategies and structuring the 5S-KAIZEN course, the fifth Stage ended with successful implementation of 5S, while the sixth Stage included evaluation and feedback.

\section{Structuring the course and the educational strategies}

This course comprised of introductory lectures on the fundamental principles of quality, the method and benefit of each step of the $5 \mathrm{~S}$, how to apply $5 \mathrm{~S}$, impact of $5 \mathrm{~S}$ on patient satisfaction, patient safety, and efficiency of the work. The teaching process of 5S-KAIZEN course is based on both theoretical sessions and practical activities at the hospital. The sources of the proposed curriculum were derived from references related to the area of 5SKAIZEN (Table 1). The practical implementations were properly performed using the available resources in the workplace. The objectives and course specification of the Public Health curriculum were revised and modified to integrate the content of 5S-KAIZEN into the content of quality and leadership. 
Table 1. References materials of the 5S-KAIZEN course.

\begin{tabular}{|c|c|}
\hline Title & Author/Year \\
\hline \multicolumn{2}{|l|}{ Change Management For Hospitals } \\
\hline $\begin{array}{l}\text { Toward Outcome-Oriented and Patient-Centered Care Under Limited } \\
\text { Resources By Participatory Management Through Stepwise Approach, 5S- } \\
\text { KAIZEN-TQM }\end{array}$ & Toshihiko Hasegawa \& Wimal Karandagoda/2010 \\
\hline 5S Pocket Guide & $\begin{array}{l}\text { Jim Peterson, Roland Smith/1998. } \\
\text { ISBN/0527763381 }\end{array}$ \\
\hline 5 Pillars of the Visual Workplace & $\begin{array}{l}\text { Hiroyuki Hirano/1995 } \\
\text { ISBN/1563270471 }\end{array}$ \\
\hline $\begin{array}{l}\text { The Executive Guide to Healthcare Kaizen: Leadership for a Continuously } \\
\text { Learning and Improving Organization }\end{array}$ & $\begin{array}{l}\text { Mark Graban/2013 } \\
\text { ISBN/9781466586413 }\end{array}$ \\
\hline $5 S$ for healthcare & Thomas L. Jackson/2009 \\
\hline $\begin{array}{l}\text { Applying the Kaizen Method and the } 5 \text { S Technique in the Activity of Post- } \\
\text { Sale Services in the Knowledge-Based Organization }\end{array}$ & $\begin{array}{l}\text { Mihail Aurel Titu; Constantin Oprean and Daniel } \\
\text { Grecu/2010 } \\
\text { ISBN/978-988812105-8 }\end{array}$ \\
\hline $\begin{array}{l}\text { Implementation Guideline for 5S-CQI-TQM Approaches in Tanzania } \\
\text { "Foundation of all Quality Improvement Programme" }\end{array}$ & $\begin{array}{l}\text { Health Services Inspectorate Unit Ministry of } \\
\text { Health and Social Welfare/2013 } \\
\text { ISBN/978-9987-737-04-8 }\end{array}$ \\
\hline 5S Implementation Guidelines in Uganda & Ministry of Health/2013 \\
\hline Manual for master trainers healthcare quality \& safety & $\begin{array}{l}\text { Directorate of healthcare quality \& safety- ministry } \\
\text { of health Sri-Lanka } / 2015\end{array}$ \\
\hline
\end{tabular}

Well-defined learning objectives were formulated to provide students with this adequate understanding of the provided subject. The students become able to understand the stages of $5 \mathrm{~S}$, listing the benefits of $5 \mathrm{~S}$ and know how to check the achievements using the $5 \mathrm{~S}$ checklist. The students will gain the practical skills by applying all the steps of 5 S activities using the available resources. Regarding the intellectual skills, the students know how to employ the tools for planning and implementation of $5 S$ activities, identify the barriers related to the implementation of $5 S$, search for online resources on $5 S$ and learn the leverage of $5 S$ in managing appropriately the working environment. Generally, the students will acquire different soft skills of effective and professional communication, teamwork building, time management, problem-solving and effective thinking; in addition to some complex skills included writing a report, how to effectively use the Power-Point and mind-mapping in displaying $5 \mathrm{~S}$ achievements. A well-trained staff with an international experience developed the learning outcomes, the timetables of the practical activities, the content and appropriate methods of teaching, length of the course, the allocating time to lectures and the field activities of the 5S-KAIZEN curriculum.

\section{IMPLEMENTATION}

The 5S related content was delivered as lectures using the Power-Point slides with activities designed around the learning outcomes. Some of the teaching and learning activities include interactive or didactic lectures, casebased examples, team-building exercises and various teaching strategies were followed in conducting the course and workshops (e.g. explanation done with modeling, and peer-tutoring). Ten hours of 5S-KAIZEN were introduced within the content of "quality in healthcare" course for 4th-grade medical students at the Public Health Department of the Faculty of Medicine, Fayoum University and were implemented over a period of one week i.e. 2 hours for successive 5 days, starting from 10th to 17th October 2016. These hours were deducted from the time allocated for teaching the course of quality. The sessions included lectures and practical case discussions. All students were divided into 17 groups 
Table 2. Course content and Instructional strategies.

\begin{tabular}{|c|c|c|c|}
\hline Content & Learning and practical activities & Instructional strategies & Delivery modes \\
\hline $\begin{array}{l}\text { (1st day/ } 2 \mathrm{hrs} \text { ) } \\
\text { 1. Introduction to 5S-KAIZEN } \\
\text { - Goal and objectives }\end{array}$ & $\begin{array}{l}\text { Assess the student knowledge and generate } \\
\text { ideas about 5S-KAIZEN }\end{array}$ & Lectures and Discussion & $\begin{array}{l}\text { - Discussion } \\
\text { - Textbook } \\
\text { - PPT presentation }\end{array}$ \\
\hline $\begin{array}{l}\text { (2nd day/2hrs) } \\
\text { 1. } 5 \text { S principles and implementation structure } \\
\text { 2. Benefits of } 5 \text { S-KAIZEN approach } \\
\text { 3. } 5 \text { S-KAIZEN approach tools }\end{array}$ & $\begin{array}{l}\text { - Identify what } 5 \text { S-KAIZEN approach stand } \\
\text { for and its principles and structure } \\
\text { - Discuss the benefits of 5S-KAIZEN } \\
\text { approach by giving different examples of } \\
\text { success in 5S-KAIZEN approach application }\end{array}$ & $\begin{array}{l}\text { - Lecture based learning } \\
\text { - Discussion } \\
\text { - Think-Pair-Share } \\
\text { - Inquiry Based Learning }\end{array}$ & $\begin{array}{l}\text { - PPT Pictures presentation } \\
\text { - Discussion }\end{array}$ \\
\hline $\begin{array}{l}\text { (3rd day/2hrs) } \\
\text { 1. 5S steps } \\
\text { - Sorting } \\
\text { - Shining } \\
\text { - Setting } \\
\text { - Standardizing } \\
\text { - Sustaining }\end{array}$ & $\begin{array}{l}\text { - Identify the different methods of } 5 \text { S- } \\
\text { KAIZEN approach and analyse their } \\
\text { characteristics. } \\
\text { - Workshops on each step }\end{array}$ & $\begin{array}{l}\text { Reporting } \\
\text { Lecture } \\
\text { Inquiry Based Learning, } \\
\text { Presentation } \\
\text { Peer-evaluation } \\
\text { Guidelines for practicing each step }\end{array}$ & $\begin{array}{l}\text { - Discussion } \\
\text { - Activity sheets } \\
\text { - Instructional materials }\end{array}$ \\
\hline $\begin{array}{l}\text { (4th day/2hrs) } \\
\text { 1. Steps for } 5 \text { S-KAIZEN implementation }\end{array}$ & $\begin{array}{l}\text {-Identify the different steps of KAIZEN } \\
\text { approach and analyse their outputs. } \\
\text { - Workshops on each step }\end{array}$ & & \\
\hline $\begin{array}{l}\text { (5th day/2hrs) } \\
\text { 2. 5S-KAIZEN assessment checklist }\end{array}$ & $\begin{array}{l}\text { - Discuss the items of } 5 \text { S-KAIZEN approach } \\
\text { checklist - Workshops }\end{array}$ & $\begin{array}{l}\text { Reporting, lecture, question and } \\
\text { answer. } \\
\text { Demonstration } \\
\text { Project-making, Peer-evaluation }\end{array}$ & $\begin{array}{l}\text { Activity sheets } \\
\text { - Instructional materials } \\
\text { - Discussion } \\
\text { - Checklist is used to assess output. }\end{array}$ \\
\hline
\end{tabular}

with an average number of 40 students in each group. The contents covered included the quality definition, theories, principles, and tools; then proceeded to the basic theoretical information of 5S-KAIZEN, history, structure, and tools. An activity guide was designated to give guidelines for both the students and the course instructors, (Table 2).

In the first stage, maps were made for the different hospital departments and handouts with full descriptions of the practical activities were given to the students with illustrative diagrams. In the second stage, the students were required to start the 5S-KAIZEN activities at the beginning of the first week of the course at selected hospital departments. In the third stage, the students standardized the forms of labeling and numbering on the computer and confirmed its shape and size under guidance of department supervisors then approved by the head of Public Health
Department and the general manager of the hospital.

The practical activities were designed to facilitate the enhancement of the students' competencies as well as their ability to make informed decisions on how to efficiently use the available resources. The first day was spent in a chosen hospital department for $5 \mathrm{~S}$ practical application. It aimed to help students become familiar with the place through performing workplace need assessment 


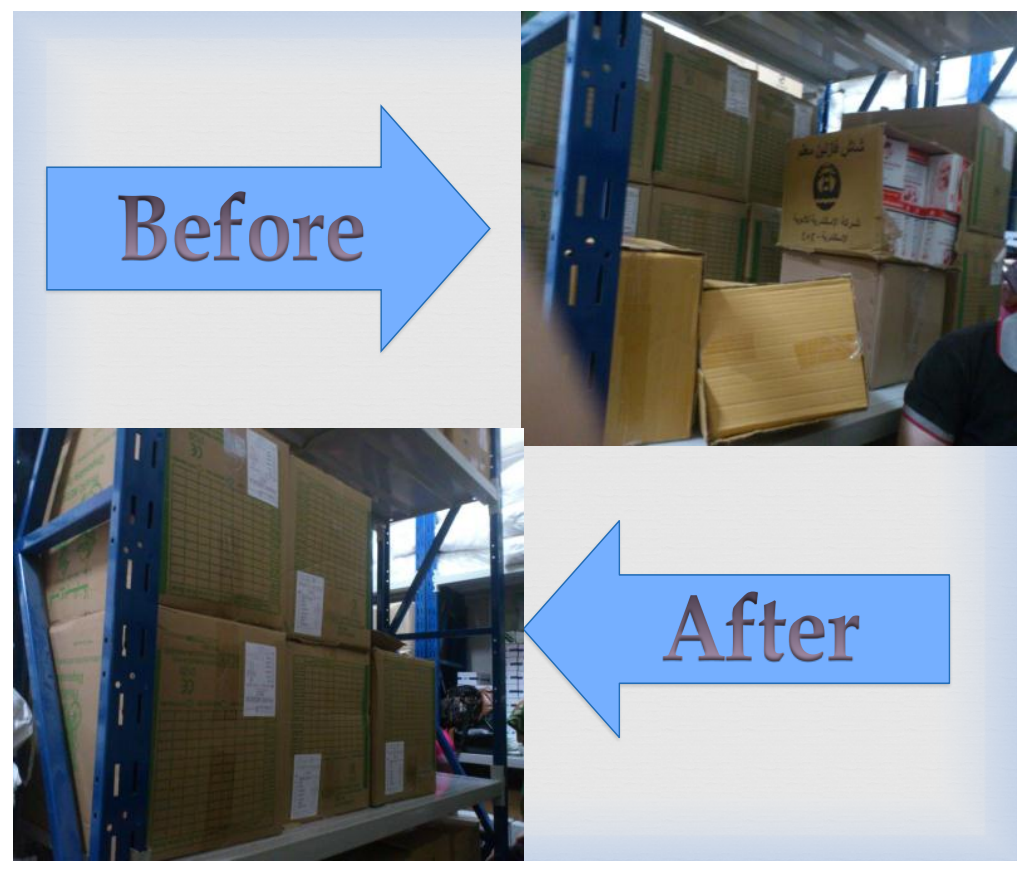

Figure 1. Students' achievement at the drug store.

followed by documenting the current situation with taking photos before implementation and encourage the healthcare personnel to be involved as partners in the process of implementation to make it more influential. On the following day, each group of students participated in eliminating the unwanted items by sorting. On the third day, students inspected the work in details so that no dust or dirt is on floor and equipment. Preparing the necessary items neatly and systematically so that they can easily be taken and returned in the original place after use, organizing, labeling and visual coding were done after all the items that do not have to be separated, by setting and shining. On the last day, students evaluated their progress in applying the $5 S$ using a standardized checklist used by DGHS (2015) to ensure that the standards are complied. The students had to take photos to show the differences of pre and postimplementation with evaluation of the established work.

A step by step guidance, peer mentoring, monitoring and supervision were provided to the whole team during the workshop's activities to reinforce and support the learning strategies, improve the acquired skills during the practical implementation and enhancing the targeted achievements over a one week period using the available resources at that department (Figures 1 to 4 ).

\section{EVALUATION}

\section{Course assessment and feedback}

The productive work of students during the course in form of group-sessions, lectures, practical activities and the written report contributes to their score. The supervisors used a quick performance checklist to evaluate students' performance during displaying the report and the picture presentation pre and post implementation of the 5SKAIZEN. The department has a documented assessment of the students' performance in order to keep continuous improvement of the course using "a performance checklist". The checklist included six criteria related to the student's knowledge; "whether the objectives were clear" and the students' productive work "whether the report was concise and descriptive, if the content was relevant and interesting, whether the presentation of pictures was well prepared, and reflected careful planning and implementation of the process. The supervisor has to evaluate the student's performance through selection one of three given choices either yes (score 2), partially yes (score 1), or no (score 0 ), and the total score is calculated at the end.

Finally, the students undergo summative assessment measures by combining the obtained marks on a paperbased test with the evaluation of the practicum, picture presentation, performance assessments and the peer evaluation. A paper-based examination was given as a mid and end term exam in addition to an end round exam; it consisted of multiple choice and simple openended questions (Table 3).

\section{OUTCOMES: BENEFITS AND CHALLENGES}

\section{Benefits}

The simplicity, practical applicability, and visual nature of 


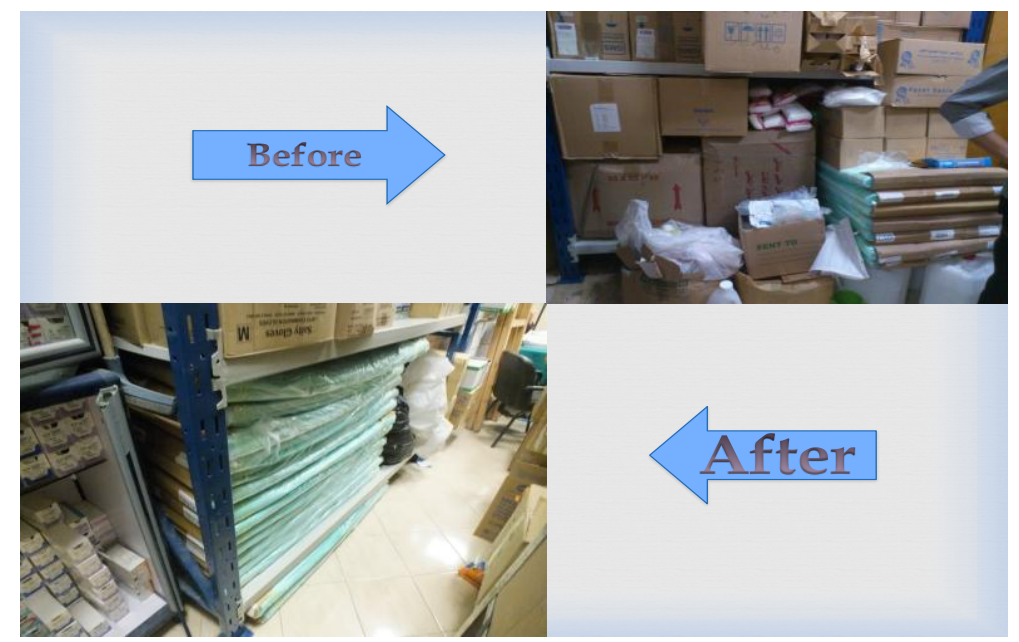

Figure 2. Students' achievements at the drug store.

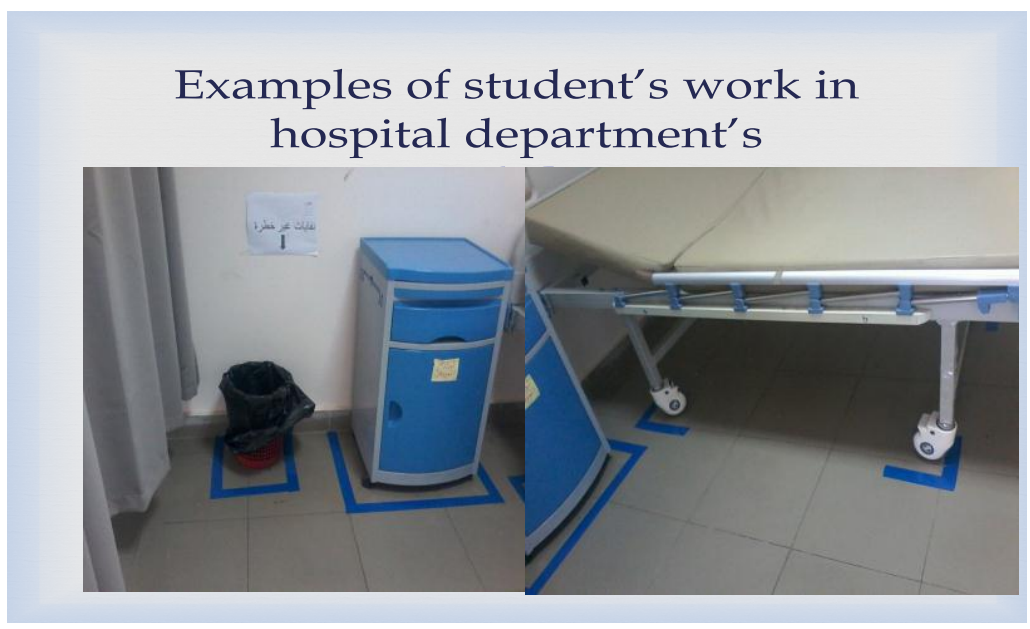

Figure 3. Students' work at outpatient clinic.

5S-KAIZEN set a foundation for Continuous Quality Improvement (CQI). The implementation success begins when the engaged medical students understand that $5 S$ needs their behavior to be adopted; everybody must to learn new things and make a continuous effort. The students learned how to manage the available resources; strengthening the role of students in decision making to be more competent and confident to put forward opinion; have the ability to critically evaluate the working environment; skilful in writing a report, and understanding the importance of leadership and team building to be successful.

A comprehensive set of learning outcomes were fostered and developed to cover different aspects of knowledge, intellectual and practical skills, commitment to personal and social responsibility and the students' learning ability to solve the workplace-related problems. These outcomes included the ability of the medical graduates to identify the five phases of $5 S$ and the goal of each, employ the tools through using effectively and efficiently the available resources in the planning and implementation activities, develop the skills of leadership, time management, problem-solving, decision-making, effective thinking and team building, check and display their achievements in applying the 5S-KAIZEN approach by a written report, power-point and picture presentation within the work environment using a checklist The ability of medical graduates to display, finally identify and explain the barriers related to the implementation of $5 S$ KAIZEN in the working environment. Different indicators are used to identify the learning outcomes. These indicators are the class discussion, the practical activities, end-course exam, assignments and the student survey.

\section{Challenges}

After the first implementation, students provided both 


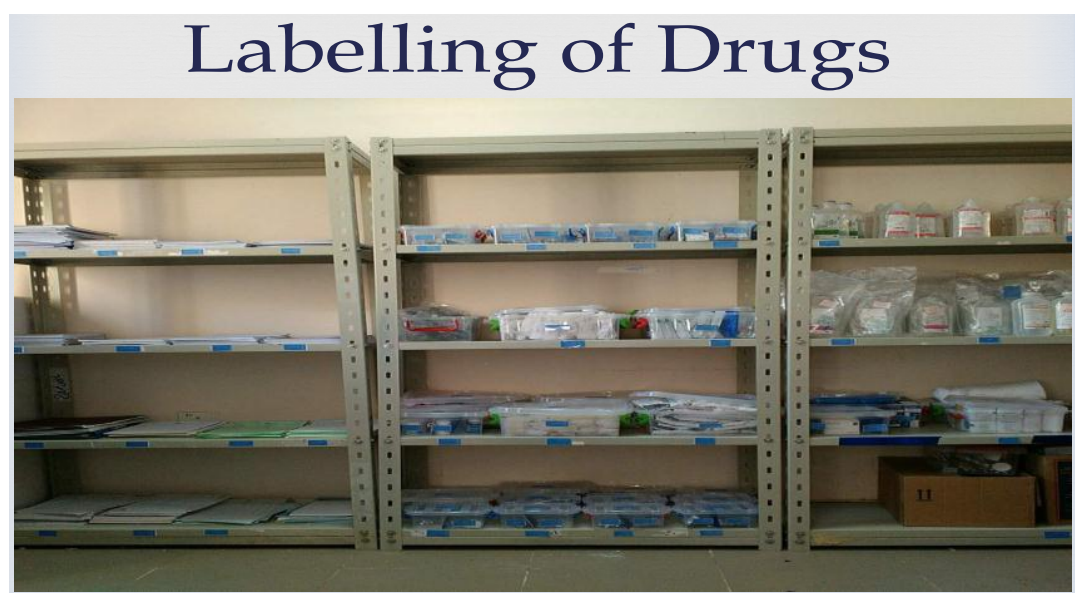

Figure 4. Students' work at pharmacy.

Table 3. Course assessment.

\begin{tabular}{lll}
\hline Categories & Description & Percentage \\
\hline Attendance & - Attendance of $80 \%$ of all theoretical and practical sessions \\
Participation & - Active participation in all 5S-KAIZEN approach activities \\
& - Presentation, with pictures documentation \\
& - Report on the practical application \\
Prelim & - Filling out the 5S-KAIZEN checklist \\
& - Mid course Exam (Multiple choice, and True/False) \\
& - End course Exam (Multiple choice, True/False, Identification, short essay questions) \\
Quiz's & - Multiple choice, True-False or Identification, Essay \\
& $100 \%$ \\
Final round exam & \\
\hline
\end{tabular}

positive and negative comments regarding the course. Negative results were related to the limited allocated time for teaching the course; limited support and cooperation provided by the healthcare personnel in the hospital during the practical application. In addition, there is a difficulty in assessing the long-term outcomes and the impact of learning 5S-KAIZEN approach on the graduate students and the working environment.

Based on students' course evaluations and the supervisors' observations, the course was revised to extend the allocated time for teaching the 5S. An orientation workshop was done for promoting the knowledge about $5 \mathrm{~S}$ among the healthcare providers in the hospital and to elicit the spirit of teamwork and cooperation and to resolve any conflicts between them and the students during of the practical activities.

\section{Impact of 5S-KAIZEN integration into the curriculum on students' knowledge, attitude and behavior}

With all the efforts at integrating 5S-KAIZEN into the
Public Health curriculum and involving the students in practical activities, we are left with the question, "what is the impact of these on student knowledge, attitudes, and behavior? To address this question, at the end of each session, students were asked to complete a selfadministered questionnaire at the end of this course to determine whether they reported significant changes in their knowledge, attitudes, and behaviors after exposure to 5S-related training activities. Exploratory analyses suggest that those medical students who were exposed to the new integrated curriculum seem knowledgeable, comfortable, and able to address the workplace needs. The survey targeted 100 students in the fourth-grade medical students. The questionnaire consisted of a total of 18 questions assess the Knowledge, Attitude, and Behavior towards 5S. The results indicated that the majority of the students agreed with the integration of the described course with a clear understanding to the goal and concepts of 5S-KAIZEN. About two third of students believed that implementation of $5 S$ reduces time and waste, increase productivity and efficiency in achieving goals. Most students said that 5S concepts became part 
Table 4. Impact of 5S-KAIZEN integration into curriculum on students KAB (100 students).

\begin{tabular}{|c|c|c|c|}
\hline \multirow{2}{*}{ Variable } & \multirow{2}{*}{$\begin{array}{c}\text { Agree } \\
\% \\
\end{array}$} & \multirow{2}{*}{$\begin{array}{c}\text { Disagree } \\
\% \\
\end{array}$} & \multirow{2}{*}{$\begin{array}{c}\text { Don't know } \\
\%\end{array}$} \\
\hline & & & \\
\hline The Goal of 5 s application is clear & 95 & 1 & 4 \\
\hline 5S should be used to organize people's need, and their work & 95 & 1 & 4 \\
\hline $5 S$ saves time and efforts & 92 & 1 & 7 \\
\hline The whole team should be involved in sort, set and shine & 95 & 7 & 2 \\
\hline $5 S$ is easy to implement and sustain & 70 & 9 & 21 \\
\hline 5S makes sense for spaces/materials which are work relevant & 98 & 1 & 1 \\
\hline 5S can be applied in any working area & 90 & 3 & 7 \\
\hline $5 \mathrm{~S}$ checklist is a useful tool to keep necessaries & 91 & 2 & 3 \\
\hline $5 S$ reduces time and waste & 95 & 3 & 2 \\
\hline $5 S$ improves communication in work place & 85 & 1 & 14 \\
\hline 5S increases productivity and efficiency & 89 & 1 & 10 \\
\hline $5 S$ activities organized my thinking & 69 & 30 & 1 \\
\hline $5 \mathrm{~S}$ can solve problems related to organizing work place & 88 & 10 & 2 \\
\hline Introducing $5 S$ into the curriculum was a great step & 78 & 2 & 20 \\
\hline $5 S$ is needed in every department in the hospital & 95 & 2 & 3 \\
\hline The practical part was sufficient to me & 87 & 5 & 8 \\
\hline Apply 5S at own living and working place & 75 & 22 & 3 \\
\hline $5 \mathrm{~S}$ became part of my attitude and behaviour & 78 & 9 & 13 \\
\hline
\end{tabular}

of their attitude and behavior (Table 4).

\section{DISCUSSION}

Medical students are considered an "under-utilized resource," needed to be involved in quality improvement projects in community-based practices (Gould et al., 2002). Integration of quality improvement teaching and engaging the medical students into every medical school curriculum was endorsed by the Academy of Royal Medical Colleges (2010), Gould et al. (2002) and Weeks (2000). As 5S-KAIZEN is recognized as a tool for quality improvement (Jugraj and Inderpreet, 2017), the students learn the effective role of planning and participation in the operational aspects of $5 S$ in long-term workplace improvement with minimal costs and disruption. Medical training basically concentrates on technical areas related to diagnosis and treatment of different diseases and rarely pays attention to support services needed for smooth functioning of the hospital (Shogo et al., 2015). Our initiative of engaging the medical students in applying the 5S-KAIZEN translates the knowledge into action.

On the first day of the course, the students were lectured with an introduction to 5S-Kaizen and detailed explanation of the goal and objectives. About three fourth of participated students clearly understood the goal and objectives of $5 \mathrm{~S}$ and agreed on the importance of introducing the $5 \mathrm{~S}$ into the medical curriculum and workplace. Students' perceptions of the world are important (Burnard, 1999; Rogers, 1983). For this reason, integration of 5S-KAIZEN teaching into Public Health curriculum is important step to provide an opportunity to equip the future doctors with the essential skills through active engagement to identify areas for improvement in our health care system.

\section{Regarding knowledge}

The results of the survey revealed that the majority of students were satisfied with the provided materials and easiness of $5 \mathrm{~S}$ practical application. More than three fourth of students found that $5 S$ is necessary to be introduced in every workplace in order to organize people's need, save time and efforts, keep necessaries, increase productivity and efficiency, reduce time and waste and improve communication.

As suggested by Shaman and Sanjiv (2014), the student-centred learning was supported by encouraging the students in actively acquiring the knowledge through exercises in class, peer mentoring, use of CAL (computer assisted learning) and interaction and participating in group discussions. The students learn how to do brainstorming in implementing the KAIZEN technique with each step of $5 S$ through setting an objective, identification then analysis the problem, finding the root cause, taking action and knowing the benefits of that action. The main objective of brainstorming is to develop the output with high quality, high productivity and lower cost (Radharamanan et al., 1996).

Furthermore, most students agreed on the importance of sustaining the $5 \mathrm{~S}$. The students learned how 
standardization lowers the maintenance and overhead costs, increase service efficiency, and improve employee loyalty to the organization and enhancing exported image of organization. The students trained on how to evaluate the performance of $5 S$ and ensuring that $5 S$ standards were met. Over the following 6 weeks, follow up was maintained to keep the previous achievements in the 5S application through sustainability to reach zero errors at work.

\section{Regarding attitude and behaviour}

More than two third of students referred to the positive impact of 5S on their thinking and the intention to use it as apart of their life. In each step of 5S approach, the students gained different values formulated their knowledge, attitude, and behavior. Application of sorting and shining required proper decision and full participation of students and the staff to choose the strategy to pursue in identification and segregation of unwanted items. Decision making and teamwork skills are key skills in professional development as reported by Academy of Royal Medical Colleges (2010).

Certain activities such as applying sorting and shining, teach the student by doing how to save space, effectively manage the time in early detecting unwanted equipment and material and make a safer and comfortable working environment. The 5S create productive work environments, clean and secure the delivery system (Shahryar, 2012). In terms of setting the students learn how to avoid the errors to faster the process and create a positive discipline. It was evident that students learned how to think positively, create new ideas so maintain high morale. Additionally, $5 \mathrm{~S}$ foster the spirit of teamwork, discipline and enhance the sense of responsibility, commitment and compassion for the organization (Shahryar, 2012).

The Japanese organizations emphasize the importance of promoting the $5 \mathrm{~S}$ practice to a wide audience as this communication. There are some variables like attitude towards kaizen events, the understanding need of kaizen, skills gained from kaizen event participation which are quite useful to measure kaizen impact on human resources (Doolen et al., 2003). The beneficial aspect of this integrated course was the opportunity provided to the future doctors to actively participate in finding solutions for real problems in the work setting and make visible positive changes in the work environment as recommended by DGHS (2015). 5S sets the foundation for building a lean health-care environment (Kaplan, 2008; Hadfield, 2006).

\section{CONCLUSION AND FURTHER IMPLICATIONS}

Integration of 5S-KAIZEN into the Public Health curriculum is an important step towards improving the communication between the medical students and the healthcare providers and develops the other soft skills. It also gave the students the opportunity to associate with other health professionals to improve the efficiency of the work climate. This was performed by transforming the academic learning of 5S-KAIZEN concepts into a meaningful practical application and creating a link between the theoretical concepts and work realities. This link played an important role in challenging the students' initial perceptions of the hospital and supporting the spirit of leadership and teamwork among them. This course will be shared with other faculties who are interested in placing the 5S- KAIZEN concepts into their curriculum. The ability to transfer the learned skills to real performance with a long-term acquisition as the course is easily transferable to other institutions and expandable to larger groups of students, continuity with post-graduate training programs and the nursing program is needed.

\section{Ethics}

This study was reviewed and approved by the Research Ethical Committee Faculty of Medicine, Fayoum University. The official approval was procured from the Dean of the Faculty of Medicine and the general managers of the Fayoum University teaching hospitals.

\section{Consent to participate}

This work was conducted after explaining its objectives to the student's participant and health care workers. Verbal ascents were taken from participants to participate in the work.

\section{Competing interests}

There is no conflict of interest as there are no commercial or financial relationships from any institution or organization that could be construed as a potential conflict and all the expenses are covered by the authors.

\section{ACKNOWLEDGEMENTS}

The investigators appreciate all who participated in implementing of $5 \mathrm{~S}$, particularly staff and students who were ambitious and had a genuine will for change and a spirit of continuous improvement.

\section{REFERENCES}

Academy of Royal Medical Colleges (2010). Guidance for Undergraduate Medical Education: Integrating the Medical 
Leadership Competency Framework. [Accessed October 10, 2016]. Available on: http://www.aomrc.org.uk/doc_view/227-undergraduateguidance-for-medical-education-integrating-the-mlcf.

Burnard P (1999). Carl Rogers and postmodernism: Challenged in nursing and health sciences. Nurs. Health Sci. 1:241247.

Chitre A (2010). Implementing the 5S Methodology for Lab Management in the Quality Assurance Lab of a Flexible Packaging Converter. The Graduate School University of Wisconsin-Stout Menomonie, WI, USA. American Psychological Association, 6th edition.

Directorate General of Health Services Ministry of Health and Family Welfare (DGHS) Bangladesh, (2015). Manual for Implementation of $5 S$ in Hospital Setting, TQM Unit, Hospital Services Management, DGHS.

Donald MB, Jonathan AF (2010). Preparing Medical Students for the Continual Improvement of Health and Health Care: Abraham Flexner and the New Public Interest. Acad. Med. 85(9):56-65.

Doolen TL, June WQ, Akan V, Eileen M, Farris JA (2003). Development of an assessment approach for Kaizen events', Proceedings of the 2003 Industrial Engineering and Research Conference, CD-ROM.

Gapp R, Fisher R, Kaoru K (2008). Implementing 5S within a Japanese Context: An Integrated Management System, Manage. Decis. 46(4):565-579.

Gould BE, Grey MR, Huntington CG (2002). Improving patient care outcomes by teaching quality improvement to medical students in community-based practices. Acad. Med. 77(10):1011-1018.

Graban M (2015). Lean Hospitals: Improving Quality, Patient Safety, and Employee Engagement, FI: CRC Press, Boca Raton.

Hadfield D (2006). Lean healthcare-implementing $5 S$ in lean or Six Sigma projects. Chelsea: MCS Media, Inc.

Huston C (2013). The Impact of Emerging Technology on Nursing Care: Warp Speed Ahead. OJIN: The Online J. Issues Nurs. 18(2):1.

Japan International Cooperation Agency (JICA), (2013). JICA's operation in health sector - present and future. Tokyo: JICA.

Jugraj SR, Inderpreet SA (2017). 5S - a quality improvement tool for sustainable performance: literature review and directions. Int. J. Qual. Reliab Manage. 34(3):334-361.

Kanamori S, Sow S, Castro MC, Matsuno R, Tsuru A, Jimba M (2015). Implementation of 5S management method for lean healthcare at a health center in Senegal: a qualitative study of staff perception. Glob. Health Action 8:1-9.

Kaplan GS (2008). Advanced lean thinking: proven methods to reduce waste and improve quality in health care. Oakbrook Terrace: Joint Commission Resources.
Kern DE, Thomas PA, Mark TH (1998). Curriculum Development for Medical Education: A Six-step Approach, Baltimore: Johns Hopkins Press.

Mallick A, Kaur A, Patra M (2013). Implementation of $5 S$ in pharmaceutical laboratory. IJPRBS 2(1):96-103.

Nimnath W, Handa Y, Karandagoda KKW, Pathirage PP, Tennakoon NCK, Pullaperuma DSP (2007). TQM emphasizing 5-S principles: A breakthrough for chronic managerial constraints at public hospitals in developing countries. Int. J. Pub. Sector Manage. 20(3):168-177.

Purdy GT, Overend C, Ball D, Wilson ML, Camelio JA, Ellis KP, Peccoud J (2013). Improving DNA Manufacturing Through Standardization. Virginia Tech and Virginia Bioinformatics Institute, VA, USA.

Radharamanan R, Godoy LP, Watanabe KI (1996). Quality and productivity improvement in a custom-made furniture industry using kaizen', Comput. Ind. Eng. 31(1/2):471474.

Rogers CR (1983). As a teacher, can I be myself? In Freedom to Learn for the 80's. Ohio: Charles E. Merrill Publishing Company.

Saeed A, Faisal S, Ithsham I, Ibtesham TH (2017). Engagement in quality improvement and patient safety - novel solutions proposed by UK-based medical students. Adv. Med. Educ. Pract. 8:109-110.

Sanders D, Welk DS (2005). Strategies to scaffold student learning: applying Vygotsky's Zone of Proximal Development. Nurse Educ. 30(5):203-7.

Shahryar S, Meysam S, Shanthi B, Hasti A (2012). Case Report: Experience of 5S Implementation. J. Appl. Sci. Res. 8(7):3855-3859.

Shaman G, Sanjiv KJ (2014). The 5 S and kaizen concept for overall improvement of the organisation: a case study. Int. J. Lean Enterp. Res. 1(1). doi: 10.1504/IJLER.2014.062280.

Shaman G, Sanjiv KJ (2015). An application of $5 S$ concept to organize the workplace at a scientific instruments manufacturing company. Int. J. Lean Six Sigma 6(1):73-88.

Shogo K, Seydou S, Marcia CC, Rui M, Akiko T, Masamine J (2015). Implementation of $5 S$ management method for lean healthcare at a health center in Senegal: a qualitative study of staff perception. Glob. Health Action.8: 10.3402/gha.v8.27256. doi: 10.3402/gha.v8.27256.

Weeks WB, Robinson JL, Brooks WB, Batalden PB (2000). Using early clinical experiences to integrate quality-improvement learning into medical education. Acad. Med. 75(1):81-84.

http://sciencewebpublishing.net/jerr 